\title{
Besov-Hankel norms in terms of the continuous Bessel wavelet transform
}

\author{
Ashish Pathak ${ }^{1}$ and Dileep Kumar ${ }^{1}$ \\ ${ }^{1}$ Banaras Hindu University Faculty of Science
}

September 25, 2021

\begin{abstract}
Using the theory of continuous Bessel wavelet transform in $\$ \mathrm{~L}^{\wedge} 2(\backslash$ mathbb $\{\mathrm{R}\}) \$$-spaces, we established the Parseval and inversion formulas for the $\$ \mathrm{~L}^{\wedge}\{\mathrm{p}, \backslash \operatorname{sigma}\}\left(\backslash \operatorname{mathbb}\{\mathrm{R}\}^{\wedge}+\right) \$$ - spaces. We investigate continuity and boundedness properties of Bessel wavelet transform in Besov-Hankel spaces. Our main results: are the characterization of Besov-Hankel spaces by using continuous Bessel wavelet coefficient.
\end{abstract}

\section{Hosted file}

Hankel Besove paper.pdf available at https://authorea.com/users/437665/articles/539144-besovhankel-norms-in-terms-of-the-continuous-bessel-wavelet-transform 